\title{
Sustainable Energy Projects and the Community: Mapping Single Building Use of Microgeneration Technologies in London
}

\begin{abstract}
Microgeneration technologies offer the potential for distributed energy supply and consumption resulting in reduced reliance on centralised generation. Adoption of microgeneration for use in community settings is usually understood as having a beneficial contribution to sustainable development. This is particularly relevant in urban environments which present specific challenges relating to the heterogeneity of building and land use. Small-scale installations in buildings also appear to offer technological flexibility at the 'human' level, necessary for local participation in shaping the direction of sustainable development. This paper reports on a project concerned with identifying on-site energy generation projects in Greater London. A database was compiled comprising renewable and energy efficient microgeneration installations in multi-occupancy buildings. The relationships between each project and its associated organisations are mapped as a social network, which illustrates the heterogeneity of technologies and actors involved, as well as the flows of funding and expertise. The structure of the resulting networks indicates a lack of participation by social or not-for-profit groups who are traditionally identified as community level actors. The findings indicate that large institutional actors on the supply side may become regarded as renewable energy experts. Hence, there is a need to consider how the concept of community level actors in urban microgeneration projects is applicable to local government and commercial organisations.
\end{abstract}




\section{Introduction}

A number of commentators have taken a positive view of the potential for urban sustainability, regeneration and transformation. For example, Girardet (1992) points out that profound change to urban environments has taken place in the recent past, which has shaped the current situation, particularly in post-war slum clearance programmes. This he takes as evidence that strong urban leadership and clear policy initiatives can effect far-reaching change, but also stresses the role of social inclusion, and co-operation to facilitate changing living and consumption practices (Girardet 1992; 1999). Blassingame (1998) is also optimistic regarding the potential for cities to embrace radical socio-technical change, pointing out the past innovations in public health and environmental utilities such as the installation of sanitation systems, clean water supply and, more recently, recycling initiatives. In terms of the prospects for environmentally sustainable change, Brunet-Jailly (2008) reports on the success of Vancouver as a city committed to sustainable development through local participation and policies that are socially progressive but fiscally conservative, which he claims have given rise to an entrepreneurial civic culture. Hodson and Marvin (2009) assert the need to reconfigure resource use, infrastructure and services in a strategic manner to achieve urban sustainability. This, for example, would mean a reduction in dependence on large scale energy generation from outside the city to smaller scale internally generated power sources, echoing Girardet's point that urban energy use is one system of production and consumption that needs reform, as 'a combination of energy efficiency and clean energy technology is critical for the sustainability of our cities' (Girardet, 1992:23).

This paper questions whether such optimism is justified, especially in the larger cities and bearing in mind that energy used in existing buildings comprises almost half of the CO2 emissions of the C40 group of cities (Arup, 2011). The C40 group includes megacities in 
countries having high GDP per capita, such as London, New York and Tokyo. It also includes megacities located in developing countries, such as Beijing, Mexico City, Mumbai and Rio de Janeiro and smaller cities in both developed and developing countries. The paper contributes to one of the concerns of the C40 group, which is to learn about what actions are being taken with what impact by cities to respond to the challenges of climate change. As well as climate change other important concerns for cities, and urban areas more generally, include economic development and 'green growth', social and economic inequality, health and community cohesion (UNEP, 2011). Crucially, celebrated successes have occurred in relatively small urban areas including less populated cities and towns (UNEP, 2011). Among these (and in relation to actions focused on energy and buildings) are Freiburg, Germany which has a population of less than 250,000 and Copenhagen which has a population of about 1.2 million.

The adoption of microgeneration systems providing on-site electricity using renewable and energy efficient technologies could contribute to this positive environmental impact at a local level in very large as well as the smaller urban locations typically invoked as examples of best practice. The role of local community actors is often considered to be a key factor in the adoption and institutionalisation of microgeneration. However, actors involved in microgeneration projects do not necessarily fit the traditional profile of community action groups. This paper raises the question of how far organisations involved in sustainable energy projects which have an impact at the local level can be considered as bona fide community actors. Furthermore, it questions whether existing conceptualisations of community actions should be extended to embrace a wider set of actors.

Some commentators argue that microgeneration is a particularly suitable means for reducing carbon dioxide emissions in urban environments (Blassingame, 1998), considering that energy 
use in domestic buildings represents up to half of the overall energy demand of cities (Kellert, 2007). Bergman and Eyre (2011) consider the potential role of microgeneration in the UK identifying advantages of small-scale on-site systems for domestic and community use. However, in the UK diffusion of microgeneration technologies is at an early stage, and a national policy to encourage adoption is a relatively recent development. At present adoption of microgeneration technologies is dominated by solar panels, both in urban and rural areas. In 2013 there were an estimated 520,000 micro-generation installations in the UK, with photovoltaic panels contributing 400,000 of the total units. This capacity provides a miniscule $0.2 \%$ of energy supplied to households (Balcombe et al, 2014). Referring to the situation in Denmark, Marszal et al (2012) suggests that, in dense urban areas, on-site use of renewable energy technologies may be limited to PV panels or micro-CHP. Hinnells (2008) also points particularly to the growth of micro-CHP units in urban areas, although there are as yet very few small installations based on biomass.

The paper undertakes analysis of a focal urban site, Greater London, to probe the nature of cityscale energy policies and community participation and how these are connected with the diffusion of sustainable technologies for energy generation and demand reduction. The study identifies and characterises urban energy projects therein and employs social network analysis to identify actors and relationships pertaining to the realisation of the projects. The resulting analysis gives an indication of the pattern of diffusion of these technologies and reveals the heterogeneity of actors involved. These results raise questions relating both to the nature of sustainable change in urban areas and to the particular contribution at the local level that can accrue from adoption and diffusion of microgeneration technologies. 
The paper is organised as follows. Section 2 reviews relevant literature, and is split into a discussion of prior research on community energy projects and then of sustainable cities and urban energy policy. Section 3 outlines the methods employed for data collection and analysis. This elaborates the approach taken to compiling a database of community energy projects in Greater London, as well as to apply social network analysis to the identification of pertinent organisational actors and relationships among them. Section 4 discusses findings from the study, set in the context of related previous work and UK and Greater London microgeneration policies. Section 5 concludes the paper, drawing together its various strands whilst making suggestions of relevance to urban and national sustainable energy policy and the promotion, design and management of community energy technology projects. It reflects on the implications of the paper for future research on urban community microgeneration.

\section{Literature Review}

\section{$\underline{2.1 \text { Community energy projects }}$}

A review of community projects undertaken between 2004 and 2006 indicated that representatives of different projects using the word community interpreted the term in different ways (Walker and Devine-Wright, 2008). Based on this data, the authors develop a classification of community energy projects according to two dimensions: process and outcome. The process dimension refers to project management, what types of actors are involved and their influence. The outcome dimension considers both the spatial and social character of the results of the projects: To what extent do 'community' benefits associated with local energy projects actually accrue to ‘the community’?

A classification of community energy projects

\section{Insert Figure 1 Here}


Walker and Devine-Wright (2008)

There are a number of observations to be made in relation to community energy projects and the Walker and Devine-Wright classification of them. First, as Walker and Devine-Wright (2008) say, the concept of 'community' should not be taken for granted. Rather, 'community' refers to 'a network of people with common interests and the expectation of mutual recognition, support and friendship’ (Barton, 2000: 5). These interest communities often have little to do with locality (Barton, 2000). Further, energy projects may be distinguished as community 'based’, ‘led’, ‘set up’ or ‘operated’. In NESTA’s ‘Big Green Challenge, 320 ‘community-led’ applications included a number which were led by professionals, some that were geographically bounded, and projects with a variety of target audiences, young people for example, some of which were only indirectly connected with the applicant groups (NESTA, 2009).

Secondly, the participatory dimension of urban energy projects may be undermined by state and local government actions, as well as by the 'local struggles' that citizens have. Indeed, while the state may offer 'structural' (e.g. financial) incentives conducive to mobilisation of community energy, the effect of doing so may be 'offset' by entrenched political interests and 'closed' policy-making practices and processes (Bomberg and McEwen (2012). Rather, greater attention to 'symbolic resources', such as the need for shared identity and community self-reliance, may provide a more effective basis for promoting community energy initiatives. Evans (2007) suggests the need for qualitative analysis of values and culture, which may be central to community identity, cohesion and action relevant to urban energy initiatives. Previous work indicates the need to identify social networks, social capital and capacity dimensions of community organisation (Peters and Jackson, 2008) and to specify what community energy and 
sustainability projects need to flourish and the relationship of this to agency (NESTA, 2009; Smith et al, 2005).

Thirdly, it is assumed that 'the public' are necessarily interested in taking an active role in urban community energy projects. Rogers et al (2008) found that members of the public perceived the benefits of community-based renewable energy in positive terms, connected with the conservation of natural resources and building of community spirit. However they also observed that, overall, citizens saw themselves as 'consultees' rather than 'project leaders' of community energy projects. In addition, the role of business actors in community energy should be considered: evidence from a research project in Scotland (Island of Lewis) suggests that the distinction between small scale community owned projects and those driven by private, corporate concerns is not clear (Murphy and Smith, 2013).

Finally, it should be noted that the dimensions included in Walker and Devine-Wright's (2008) framework do not address the technical characteristics of community energy projects but the social arrangements regarding their ownership and management. However, the co-construction of the social and technical characteristics of community energy may need to be reconsidered, which is a core task of the paper.

\subsection{Sustainable cities and urban energy policy}

In terms of energy policy local actions might not integrate well with different levels of policy objectives. There is a need to examine whether energy policies differ between national and urban levels and how cities can contribute to global policy goals (Keirstead and Schulz, 2010). Community renewable energy has been positioned as an integral part of UK energy policy, with schemes such as the Community Renewables Initiative providing funding and support towards this goal (Walker et al, 2007). The increasing prominence of the term suggests a shift from 
large-scale centralised energy systems (Devine-Wright, 2007) as microgeneration and community energy schemes substitute for insufficient, ineffective state efforts. Indeed, in relation to renewable energy, cities have been described as "islands of opportunity in seas of decay” (Nijkamp and Pepping, 1998:1481), since administrative coherence, interest in resource and environmental issues, and the co-location of energy production and consumption make cities ideal sites for the evaluation of energy policies.

Guy and Marvin (1999) contrast 'singular' and 'multiple' visions of the sustainable city, where the former relies on overcoming barriers to implementing policies designed in City Hall and 'policing' to monitor the attainment of targets set 'top-down'. Multiple visions, however, rely on partnership and the development of coalitions of interest with a range of participants across the city. With particular regard to local authorities,, Bulkeley et al (2011) observe that in the UK local governments are becoming more self-sufficient in using natural resources, and adept at utilising local knowledge to inform policy-making. They are also engaging in cross-national networks, which enable them to learn from others about how to improve local policies for sustainability. Kellert (2007) blames the failure of top down policy instruments and resistant markets for a slow move away from fossil fuel use in cities that are characterised by highenergy use and low energy production. Jänicke (2008) supports the use of strong environmental regulations to act as a driver for innovation by setting out a set of achievable standards. For Jänicke (2012) clear policies can promote market development for environmental innovations by improving the operational aspects of installed technologies, for example from setting and gaining compliance to technical standards. Janicke points to the variation in national success in changing practices in energy generation and use as a result of differing emphasis in national policies. Blassingame (1998) also states that renewable energy generation and increased energy efficiency measures are equally achievable provided there is a coordinated strategy for change. 
These points are supported by Hinnels (2008) who asserts that microgeneration diffusion requires a mix of clear policy objectives, innovation market development and financial support.

Despite these thoughts regarding the ability of the self-governing, participative city to enact environmentally sensitive changes, the role of specific urban energy policies tends to be overlooked despite the fact that cities account for two-thirds of global primary energy consumption (Keirstead and Schulz, 2010). In the UK there is no single national policy which covers on-site microgeneration technologies. The defined capacity of micro-generation technologies is stated in the UK Green Energy Act, 2009. Small power generating systems are those that generate up to $50 \mathrm{~kW}$ of electricity and $300 \mathrm{~kW}$ of heat. The Department of Environment and Climate Change (DECC) 'Energy Roadmap’ states the objective that $15 \%$ of energy consumption will be provided by renewable sources by 2020. This objective is to be met through provision of low-carbon electricity from a range of sources, in addition to reduction of demand through energy efficiency measures DECC (2011). There are a number of microgeneration technologies that could contribute to this mix, including photovoltaic panels (PV), solar thermal heating, micro-turbines, biomass boilers, micro-combined heat and power (CHP) and ground and air heat pumps as technologies currently suitable for individual dwellings (Bergman and Eyre, 2011). However, the UK feed-in tariff which compensates for electricity supplied to the National Grid from micro-generation has favoured the installation of photovoltaic panels in the UK. A national strategy to encourage diffusion of microgeneration technologies was published in 2011 (DECC 2011). Amongst the issues identified in the Microgeneration Strategy is the need to strengthen the existing Microgeneration Certification Scheme (MCS). Also necessary are moves to improve consumer protection policies, and the need to support training, knowledge and skills within the industry to meet increasing demand for small unit installation. In addition, the need for continued technological innovation was 
noted, along with the need for initiatives to raise awareness of potential customers to the available opportunities. A recent government report on UK community energy strategy discusses the role of communities as producers of heat and electricity as well as community involvement in reducing energy use, demand management and energy purchasing (DECC 2014). At the regional level in London, the Greater London Authority (GLA) and various local boroughs have adopted targets for the adoption and use of onsite power generation technologies. The Mayor of London (2013) notes the commitment to work towards making London a thriving low carbon capital, with a target of $25 \%$ of energy supply to be achieved from distributed sources by 2025. The current London Plan (Mayor of London, 2011), has a target of $20 \%$ of energy in new build to be generated from onsite renewable or through energy efficiency measures.

\section{Research methods}

This section outlines the research methods employed in the present study. The study aims to identify patterns in the diffusion of community energy and microgeneration technology in urban locations. The site of Greater London is selected because its decentralised governance structure helps to examine how policy initiatives at different levels contribute to urban micro-generation viz national level policies, and policies developed at the metropolitan level and by individual boroughs. Furthermore, the plurality in fuel sources and energy conversion technologies found in London micro-generation projects makes it an interesting site to examine variation in urban community energy initiatives. Micro-focused engagement or project-specific case study approaches would not be suitable for meeting the project aim. Surveys of community energy actors may allow for comparisons between projects and point to factors affecting the success of renewable technologies. Unlike case studies, surveys may provide an overview of community energy in a particular geographical setting or focus on a particular renewable technology. 
However, unlike surveys (c.f. Seyfang et al, 2012; Walker et al, 2005), this study adopts a relational perspective, employing social network analysis (SNA) to examine Greater London community energy projects and associated actors. Emphasis is placed on the links between technologies, projects and different types of organisational actors and how these enable knowledge sharing. The use of a relational, network approach bypasses the dichotomy between qualitative case studies and quantitative, survey-based methods (Cambrosio et al, 2004). The relational approach advocated is an alternative to both qualitative, ethnographic studies of community energy projects and to survey-based approaches.

Microgeneration projects may be supplemented by energy demand reduction initiatives at the community level (DECC, 2014). However, this study refers to energy demand reduction only in cases where such activities are combined with a microgeneration project. Data regarding the current status of community energy microgeneration projects in London were collected from publicly available sources, such as planning applications to local councils, company documents and the DECC website. Social network analysis methods were then applied to the visualisation and analysis of the data; large amounts of qualitative information about the actors and their relations were summarised in the graphical format of network maps.

Fundamentally, SNA is employed to address the following research questions:

1. What community and microgeneration renewable energy technology projects are being undertaken in Greater London?

2. What actors are involved in such activities, why and with what effect? To what extent and how are actors and projects connected and with what implications for promotion and diffusion of community and microgeneration renewable energy technology projects?

3. What is (or what should be) the role of residents and community actors in such activities? 
The methodology includes the following stages:

- Identification of community energy projects and related organisational actors in the metropolitan area of Greater London

- $\quad$ Classification of both the projects and the associated organisations

- $\quad$ Construction of network databases noting the links between organisations and projects and visualisation of the resulting networks

- Analysis of the networks in order to identify the degree of cohesion and heterogeneity, and indicate organisations/projects holding prominent network positions.

According to the socio-spatial concept of an area (Murphy and Smith, 2013) the selected projects were Greater London-based: although some installations are not located physically within the Greater London geographical boundaries, their energy source may be a by-product of Greater London-based activities (as in the case of some waste management projects). Following Callon (1992) actors may be defined empirically. A database of projects was constructed using non-obtrusive methods of data collection relying mostly on publicly available data (e.g. from the Department of Energy and Climate Change, the Renewable Energy Association and local authorities). Information from planning applications was used to describe the current state of various projects. Organisational actors associated with the projects were subsequently identified on a basis similar to that of a snowball method (Heckathorn, 2002): organisations were included in the network only where there was a defined link with an already identified project. Hence, community energy projects are the primary units of analysis or the actors that one follows to map the Greater London community energy landscape.

Arguably, a different representation of the network may have emerged if organisations had been selected as the primary points of analysis instead of projects. Network boundaries are 
problematic to identify and there is inevitably a degree of subjectivity in their selection. Unlike systems, networks are in principle unbounded, yet it is necessary to specify limits for analytical purposes (Conway and Steward, 1998). First one has to decide the rules of inclusion in the network or as termed by Laumann et al (1983) "the definitional focus”. In this case, projects were selected according to geographical location (Greater London), evidence of renewable energy use and their generating capacity (small to medium). Since the term community energy is subject to interpretation, projects were not included solely because they demonstrated evidence of community engagement. Indeed DECC (2014) suggests that the definition of community energy may be expanded to include projects instigated by local authorities, housing associations or local businesses. We would not claim that the aforementioned rules of inclusion provide a definitive account of community energy in Greater London. Adopting different criteria regarding the selection of projects would lead to the enactment of alternative realities: realities and their representations are not independent of the research process that generates these representations (Law, 2004). In that sense, interpretations of the term "community energy" affect the definition of the questions, while the term itself is subject to redefinition in the light of analysis and findings produced.

Both the organisations and the projects were classified according to certain criteria. The organisations were categorised according to their organisational type (businesses, local or central government actors and civil society organisations such as community groups). In addition, organisations are classified in terms of their relation to the projects: they can be linked to a project as funders, as clients/users of the generated energy or as technology developers. Information on the power generation capacity of the projects was added where available. However, information on the energy generating capacity was in some cases either missing or unclear since different sources provided different estimations. Information is also available on 
the intended energy use (domestic or office use; heat, power or both). The projects are classified according to a combination of energy source and energy conversion technology. The classification leads to the following categories of projects:

- $\quad$ Solar energy (power or hot water generation)

- $\quad$ Wind turbine

- $\quad$ Geothermal energy

- Landfill gas or biomass anaerobic digestion (biological rather than thermo chemical energy conversion)

- $\quad$ CHP (using biomass or waste)

- $\quad$ Biomass or waste incineration

- $\quad$ Hydro energy

- $\quad$ Hybrid projects (e.g. combining PV panels and a wind turbine)

SNA was employed to examine characteristics regarding technology diffusion. The concepts of homophily and heterophily were applied to demonstrate how the characteristics of network actors affect the potential for innovation. Homophilous networks where actors share the same attributes are more likely to lead to standardisation in technology choices, while participation in heterophilous networks is more likely to expose actors to new ideas. Ideally, a balance between homophily and heterophily should exist in order for a network to be effective in nurturing innovation (Callon, 1992; Granovetter, 1985), though increased homogeneity and standardisation are likely to exist in a denser, more cohesive network (Granovetter, 2005). Here the role of homophily versus heterophily in the network of organisations is evaluated by counting the number of external ties (between organisations of the same type) minus internal ties (between organisations of different types) as a proportion of all ties in the network ( the E-I index measure by Krackhardt and Stern, 1988). Hence, the value of the E-I index is -1 in a 
network dominated by internal ties. In terms of the network of projects and actors involved in community energy in Greater London, the co-existence of multiple technologies and actors of different organisational characteristics is used to evaluate the level of heterogeneity; however, heterogeneity is not seen as an obstacle to the diffusion of sustainable energy technologies. SNA techniques were applied to identify potential sociotechnical trajectories by observing the structural pattern of network relations. Subsets of the aggregate network that are characterised by increased levels of cohesion suggest that actors within the same subset are more likely to share expertise and share similar views on the implementation of community microgeneration (Burt, 1992; 2004). The approach taken here identifies network 'components', in other words subsets of a network where there is at least one path of links that connects any two given nodes (de Nooy et al, 2005). Finally, network centrality measures are used to identify actors that hold more influential positions. These actors are positioned as gatekeepers in the flows of expertise and funding in the aggregate network, which can act as bridges between actors and effect collective action (Moss, 2009). Hargreaves et al (2013) suggest that community energy intermediaries deploy diverse ways in diffusing generic lessons from projects developed in specific contexts. Betweenness centrality analysis was used to identify central actors as this centrality measure is more suitable to identify actors with the potential to act as mediators (Knoke and Yang, 2008).

\section{Microgeneration and community energy projects in Greater London}

Projects, Networks and Actors

The secondary research identified 93 microgeneration projects in Greater London (approximately within the area bounded by the M25 orbital motorway). Each project is linked to a number of organisational actors. 86 of the projects were included in the analysis; projects 
were excluded if proposers did not gain planning permission, withdrew their planning application or abandoned projects. The resulting database includes only operational projects and projects awaiting construction. Initially, a bipartite network was constructed that includes both projects and organisational actors: the bipartite network only includes links between organisations and projects. The visualisation does not distinguish between the types or strength of the linkages between organisations and projects; only the presence or absence of a linkage is indicated. For reasons of visual clarity, only network components with at least four nodes (organisations or projects) are included.

Figure 2: London community energy projects and linked organisations

\section{Insert Figure 2 here}

Key: White circles=projects, black squares=organisations

The network is divided into different components. A number of major actors in some components are highlighted in Figure 2. Communication and exchanges between organisations in the same component are possible even if the actors are not involved in the same projects. On the other hand, interaction between actors in different components is not possible on the basis of the linkages that have been mapped in this network. Yet, the network represents concrete evidence of involvement in particular renewable energy installations: there is the possibility that actors in different components may have forged looser, more informal linkages through alternative networks.

The participation of utility companies (Veolia, Thames Water) is observed in two of the components. These companies are involved in fairly large-scale projects in terms of capacity. The network component including Veolia (top left in Figure 2) demonstrates the company's 
involvement in a number of projects (including landfill gas, energy from waste and CHP). Their involvement in the South East London Heat \& Power (CHP) plant provides a bridging link to a number of projects involving boroughs in South East London. Thames Water (mid left side) is also involved in CHP, but also in solar and wind energy projects.

Other network components include retailers (IKEA, Sainsbury's) and local councils, which have a strong presence. However, participation of Greater London-wide or central government organisations is more limited. Regarding the involvement of corporate actors, Ford has invested in wind turbines and biomass/waste incineration in its Dagenham plant in partnership with organisations that could provide technical expertise (lower right side in Figure 2).

The bipartite network provides more detailed information on the current state of community energy in London; however, the identification of patterns is better achieved through the examination of two separate one-mode networks: the network of projects and the network of organisations. In the visual representations of these networks the strength of the link between two organisations represents the number of projects they are jointly involved in. Similarly, projects are linked when they both have links to the same organisations. Figure 3 includes the network of organisations.

Figure 3: London community energy actors

\section{Insert figure 3 here}

Key: circles=business actors, square=central government, boxes=local government, triangles $=$ civil society

There is a dominant presence of business actors in the network of organisations and very limited presence of civil society actors (Riverside community, Bioregional, Brixton Energy 
Coop), that one would expect to have a co-ordinating role in community energy projects. Businesses are involved both as technology developers (for instance, engineering and architecture firms) but also as users of community energy. There is a strong presence of local government actors (22 organisations); it is arguable that the presence of local government serves a function in promoting/financing community energy that one would expect community groups to fulfil. It is evident from the visualisation that particular actors/links play a mediating role in components of the network. Still, some components are too small to have any significant influence.

With regard to issues of homophily and heterophily the data indicate that there is a tendency towards internal ties (homophily) to a degree that is slightly higher than expected for a network of this size and group composition: the observed E-I index is nearer the value of -1 than would be expected in a random network. This results primarily because business organisations, which dominate the network, tend to link to other businesses. Government (national and local) and civil society associations are more likely to form out-group ties, usually with businesses. Although the network is fragmented into components there is evidence of cohesion at the local level as transitivity is high: when two actors are linked to the same third actor, they will be directly connected themselves in $67.43 \%$ of cases.

A number of actors with high betweenness centrality are identified (such as EDF, Vital Energi, LB Southwark) however their role is limited to their respective components. Hence, network centralisation (the dependence of the network on particular central actors) is very low. Since the network is disconnected there is a lack of intermediaries at the global level. This observation is consistent with the view that there is a lack of centralised mechanisms for the implementation of community energy policies. 
The network of projects is represented in Figure 4 but does not include isolated nodes (unconnected projects). Here, there is a strong presence of CHP technology (up triangles-24 projects) and solar energy (PV panels) installations (circle nodes-19 projects).

Figure 4: London community energy projects featuring technologies

\section{Insert figure 4 here}

\section{Figure key}

\begin{tabular}{|l|l|}
\hline Biomass/waste incineration & Inverted triangle \\
\hline CHP & Triangle \\
\hline Geothermal & Cross \\
\hline Hybrid & Circle in box \\
\hline Landfill gas or AD & Diamond \\
\hline Solar & Circle \\
\hline Wind & Square \\
\hline
\end{tabular}

The number of CHP projects indicates a potential pathway towards this technology although there are limited links among projects of this type. One component of the network includes the projects financed by Thames Water. Another component includes a set of anaerobic digestion projects (diamond shaped nodes-16 projects) using landfill gas. The literature review suggested limited uptake of biomass yet it appears that anaerobic digestion/biogas projects are more established than predicted. The incentives behind these projects may relate mostly to concerns about appropriate methods of waste disposal (other than landfill) than with energy issues. Regarding the role of isolated projects these can only have limited effects on the evolution of the network since they lack links to other projects. Although the actors involved in such a project exchange expertise and resources, they cannot benefit from experience developed in other projects. It could be the case that some of these actors are involved in non-London based projects. Even so, they would lack access to information about the particular requirements of 
microgeneration in Greater London. As outlined in earlier sections, there are particular policy issues regarding sustainable energy in an urban environment.

Like the network of organisations, the network of projects also indicates high transitivity (55.96\%). Although the overall network is disconnected there is potential for knowledge exchange at the local level. In addition, analysis of the prevalence of in-group versus out-group ties shows that projects are more likely to be linked to projects of the same energy type to a greater extent than would be expected in a random network: considering that projects are linked through organisations this suggests that organisations are more likely to engage with a particular technology.

\section{Discussion and Conclusion}

The section reflects on the findings of the study, as they pertain to the contribution to knowledge it makes regarding the nature of community energy or microgeneration projects and the specific research questions underpinning the project. Overall, the paper finds that the classification of 'community' urban energy projects is more complicated than was apparent in the earlier work of Walker and Devine-Wright (2008). For example, in relation to 'process' issues it is necessary to unpack notions of ownership of and involvement in local energy generation initiatives. There 'are many forms of project being given the community label' as Walker and Devine-Wright (2008: 499) recognised but this heterogeneity requires closer scrutiny.

The first research question concerns the content of microgeneration projects. On the basis of the analysis presented here, relating to selected microgeneration projects in Greater London, the content of initiatives varies widely in scale, technology and purpose. However, projects featuring combined heat and power technology dominate, a finding consistent with Hinnels' 
(2008) remarks regarding the suitability of CHP in cities. Thus their popularity in London is expected. In relation to the second research question, the paper shows that in many projects the central actors are not residents, local activists, or energy firms. In terms of 'outcomes', the accrual of benefits from the projects needs to be set in the light of the identity and interests of promoters, whose orientation had much to do with waste or water resource management, for example, rather than energy reduction or generation per se. Here one sees the centrality and motivation of specific non-energy focused firms and utilities, such as: Veolia (waste management); Viridor; and Thames Water (which had land resources available and funding necessary to support Crossness and Beckton projects, for example). This is consistent with the observation that the development of anaerobic digestion is partly driven by the need to reduce waste sent to landfill (Levidow and Papaioannou, 2013). Projects run by non-energy corporations demonstrate how energy is linked to the provision of other public services such as waste management and sanitation, so that more integrated policies may be necessary. Recognising this, it appears that the social character of benefits to 'the community' connected with heat or electricity supply are by-products of project activities driven by other concerns. There is a spatial dimension in that the main promoters are organisations that are distant from the communities being served by the projects by dint of the international nature of their ownership and spread of activities.

The third research question related to the role of community and other actors, and to the relationships among actors and projects. Here, the paper showed that the LDA development agency and regional and borough councils assumed a more significant coordinating role than either central government or London-wide bodies such as the London Assembly or the Mayor of London's office. Specific local initiatives are thus partly shaped by the activities of local councils and the business strategies of large national and international corporations, and much 
less by community organisations or private residents. Project level learning is impaired since the network lacks actors that could play a central co-ordinating role and transfer expertise between projects in different boroughs. The isolated character of some projects further exacerbates this problem. It could be argued that local councils have a mediating but contradictory role in both representing and supporting but also silencing local communities.

The majority of the projects rely on more popular renewable energy technologies such as CHP and PV rather than more untested technologies such as heat pumps. The participation of local authorities in a substantial number of projects indicates a potential pathway of institutional arrangements for community energy where local authorities may substitute for the lack of London-wide co-ordinating actors. The engagement of large corporate actors suggests a pathway more compliant with the distant and private/closed and institutional quadrant in the Walker and Devine-Wright (2008) typology.

Our representation indicates a lack of actors that are conventionally classified as community (community groups, social enterprises, residents association). However, their paucity does not necessarily indicate that they bear no influence on community energy developments. As Rogers et al (2008) note, community actors may not wish to take the initiative regarding the development of projects but retain a more discreet role. The strong presence of local government actors would suggest that they represent the local communities through the political and planning process. Energy utilities are an additional group of actors with minimal representation in the network. However, this may attributed to the relatively small scale of the selected projects. 
Reflecting on the above, it is apparent that in the future research should examine and categorise the different promoters of and motives for ostensibly community-driven initiatives, and tease out the various roles that they and other actors play in related projects, as well as interactions among them and the activities they perform. This will require scrutiny of the purposes, work and networking of (local) governmental organisations, waste, building and energy companies, and community groups and residents in urban energy and related community projects, as this relates to policy-making as well as to activities 'on the ground'. A benefit of doing so could be to generate further insight into the relative merits or complementarity of micro-, meso- and macro-level studies of community energy, by examining the conventions, assumptions and practices which constitute behaviour of and relations among protagonists, or which leave others out, mindful of wider patterns of change. The accomplishment of the latter in terms of the adoption of more sustainable energy technologies is in itself only part of the story. Without attention to their effective use in practice mere installation of sustainable urban or microgeneration energy technologies will not make the required contribution to climate change targets. This aspect, too, requires further examination from the perspective of adopting a longitudinal approach tracing developments through from project gestation to post-adoption everyday use. 


\section{$\underline{\text { References }}$}

Arup (2011) Climate Action in Megacities, C40 Cities: Baseline and Opportunities.

Available at: http://www.C40cities.org. Last accessed 19 September, 2014

Balcombe, P, Rigby, D and Azapagic A (2014) Investigating the importance of motivations and barriers related to micro-generation uptake in the UK, Applied Energy 130: 403-418 Barton H (ed.) (2000) Sustainable Communities. London: Earthscan.

Bergman N and Eyre N (2011) What role for microgeneration in a shift to a low carbon domestic energy sector in the UK? Energy Efficiency 4 (3): 335-353.

Blassingame L (1998) Sustainable Cities: Oxymoron, Utopia, or Inevitability? Social Science Journal 35 (1): 1-13.

Bomberg E and McEwen N (2012) Mobilising community energy. Energy Policy 51: 435-444. Brunet-Jailly E (2008) Vancouver: The sustainable city Journal of Urban Affairs 30 (4): 375388.

Bulkeley H, Broto VC, Hodson M and Marvin S (2011) Cities and the low carbon transition. The European Financial Review August-September 24-27.

Burt RS (1992) Structural holes: The Social Structure of Competition. Cambridge: Harvard University Press.

Burt RS (2004) Structural Holes and Good Ideas. The American Journal of Sociology 110 (2): 349-399.

Callon M (1992) The dynamics of Techno-economic networks. In: Coombs R, Saviotti P, Walsh V (eds) Technological change and company strategies: economic and sociological perspectives. London: Academic Press, pp. 73-102.

Cambrosio A, Keating P and Mogoutov A (2004) Mapping Collaborative Work and Innovation in Biomedicine: A Computer-Assisted Analysis of Antibody Reagent Workshops. Social Studies of Science 3 (3): 325-364. 
Clark D (1996) Urban World/Global City. London: Routledge.

Conway S and Steward F (1998) Mapping Innovation Networks. International Journal of Innovation Management 2 (2): 223-254.

DECC (2011) Microgeneration Strategy. Department of Environment and Climate Change, June.

DECC (2011) Energy Roadmap, July, Department of Energy \& Climate Change, 3 Whitehall Place, London SW1A 2AW

DECC (2014) Community Energy Strategy: Full Report. Department of Environment and Climate Change, January.

De Nooy W, Mrvar A and Batagelj V (2005) Exploratory social network analysis with Pajek. Cambridge: Cambridge University Press.

Devine-Wright P (2007) Domestic energy sector in the UK? Energy Efficiency 4 (3):335-353 Evans D (2007) Attitudes, values and culture: qualitative approaches to 'values' as an empirical category. RESOLVE working paper 04-07. Guildford, RESOLVE Research Centre, February Girardet H (1992) Cities: new directions for sustainable living. London: Gaia Books.

Girardet H (1999) Creating Sustainable Cities. Devon: Green Books, Devon. Granovetter M (1985) Economic Action and Social Structure: The Problem of Embeddedness. The American Journal of Sociology 91 (3): 481-510.

Granovetter M (2005)The Impact of Social Structure on Economic Outcomes. Journal of Economic Perspectives 19 (1): 33-50.

Guy S and Marvin S (1999) Understanding sustainable cities: competing urban futures. European Urban and Regional Studies 6 (3): 268-275.

Hargreaves T, Hielscher S, Seyfang G and Smith A (2013) Grassroots innovations in community energy: The role of intermediaries in niche development. Global Environmental Change 23 (5): 868-880. 
Heckathorn DD (2002) Respondent -Driven Sampling II: Deriving Population Estimates form Chain-Referral Samples of Hidden Populations. Social Problems 49 (1):11-34.

Hinnells M (2008) Combined heat and power in industry and building. Energy Policy 36 (12): $4522-4526$.

Hodson M and Marvin M (2009) Urban Ecological Security: A New Urban Paradigm?

International Journal of Urban and Regional Research 33 (1): 193-215.

Jänicke M (2008) Ecological modernisation: new perspectives. Journal of Cleaner Production 16 (5) 557-65.

Jänicke M (2012) Dynamic governance of clean-energy markets: how technical innovation could accelerate climate policies. Journal of Cleaner Production 22 (1): 50-59.

Keirstead J and Schulz N B (2010) London and beyond: Taking a closer look at urban energy policy. Energy Policy 38 (9):4870-4879.

Kellert J (2007) Community-based energy policy: A practical approach to carbon reduction. Journal of Environmental Planning and Management 50 (3): 381-396.

Knoke D and Yang S (2008) Social network analysis, 2nd edition. Los Angeles, Calif.; London: Sage.

Krackhardt D and Stern RN (1988) Informal networks and organizational crises: an experimental simulation. Social Psychology Quarterly 51(2): 123-140.

Laumann EO, Marsden P and Prensky D (1983) The boundary specification problem in network analysis. In: Burt R and Minor M (eds) Applied Network Analysis: A Methodological Introduction. Beverly Hills: Sage, pp. 18-34.

Levidow L and Papaioannou T (2013) State imaginaries for the public good: shaping UK innovation priorities for bioenergy. Environmental Science \& Policy 30: 36-49. 
Marszal, A J, Heiselberg, P, Jensen R L, Nørgaard, J (2012) On-site or off-site renewable energy supply options? Life cycle cost analysis of a Net Zero Energy Building in Denmark, Renewable Energy, 44, 154-165

Mayor of London (2011) London plan: Delivering London's energy future. London: Greater London Authority, http://www.london.gov.uk/sites/default/files/Energy-future-oct11-exec$\underline{\text { summ.pdf }}$ Mayor of London, 2013 District heating manual for London, Greater London Authority NESTA (2009) Research Summary: People-powered responses to climate change: mapping community-led proposals to NESTA's big green challenge. London: NESTA.

Moss T (2009) Intermediaries and the governance of sociotechnical networks in transition. Environment and planning A 41(6): 1480-1495.

Murphy J and Smith A (2013) Understanding transition-periphery dynamics: renewable energy in the Highlands and Islands of Scotland. Environment and planning A 45 (3) 691:-709. Nijkamp P and Pepping G (1998) A meta-analytical evaluation of sustainable city initiatives. Urban Studies 35 (9): 1481-1500 .

Peters M and Jackson T (2008) Community action: a force for social change? Some conceptual observations. RESOLVE working paper 01-08, Guildford, RESOLVE Research Centre. Rogers JC, Simmons E A, Convery I and Weatherall A (2008) Public perceptions of opportunities for community-based renewable energy projects. Energy Policy 36 (11): 42174226.

Seyfang G, Park J J and Smith A (2012) Community Energy in the UK. 3S Working Paper 2012-11, Norwich: Science, Society and Sustainability Research Group, http://grassrootsinnovations.files.wordpress.com/2012/10/3s-wp-2012-11-cise.pdf Smith A, Stirling A and Berkhout F (2005) The governance of sustainable socio-technical transitions. Research Policy 34 (10): 1491-1510. 
UNEP (United Nations Environmental Program) (2011) Cities: investing in energy and resource efficiency, UNEP

Walker G and Devine-Wright P (2008) Community renewable energy. What should it mean? Energy Policy 36 (2): 497-500.

Walker G, Devine-Wright P, Evans B (2005) UK Community Energy Projects database.

Community Energy Initiatives,

http://geography.lancs.ac.uk/cei/CommunityEnergyUKProjects.htm

Walker G, Hunter S, Devine-Wright P, Evans B and Fay H (2007) Harnessing Community

Energies: Explaining and Evaluating Community-Based Localism in Renewable Energy Policy in the UK. Global Environmental Politics 7(2): 64-82

\section{Disclaimer}

The social network maps are based on data supplied from an Excel database compiled from open access and publically available data. This database is maintained by the authors and access available by e-mail to the corresponding author. 